\title{
Endoscopic ultrasound-guided repositioning of
}

\section{a migrated metal hepatogastrostomy stent using}

\section{foreign body forceps}
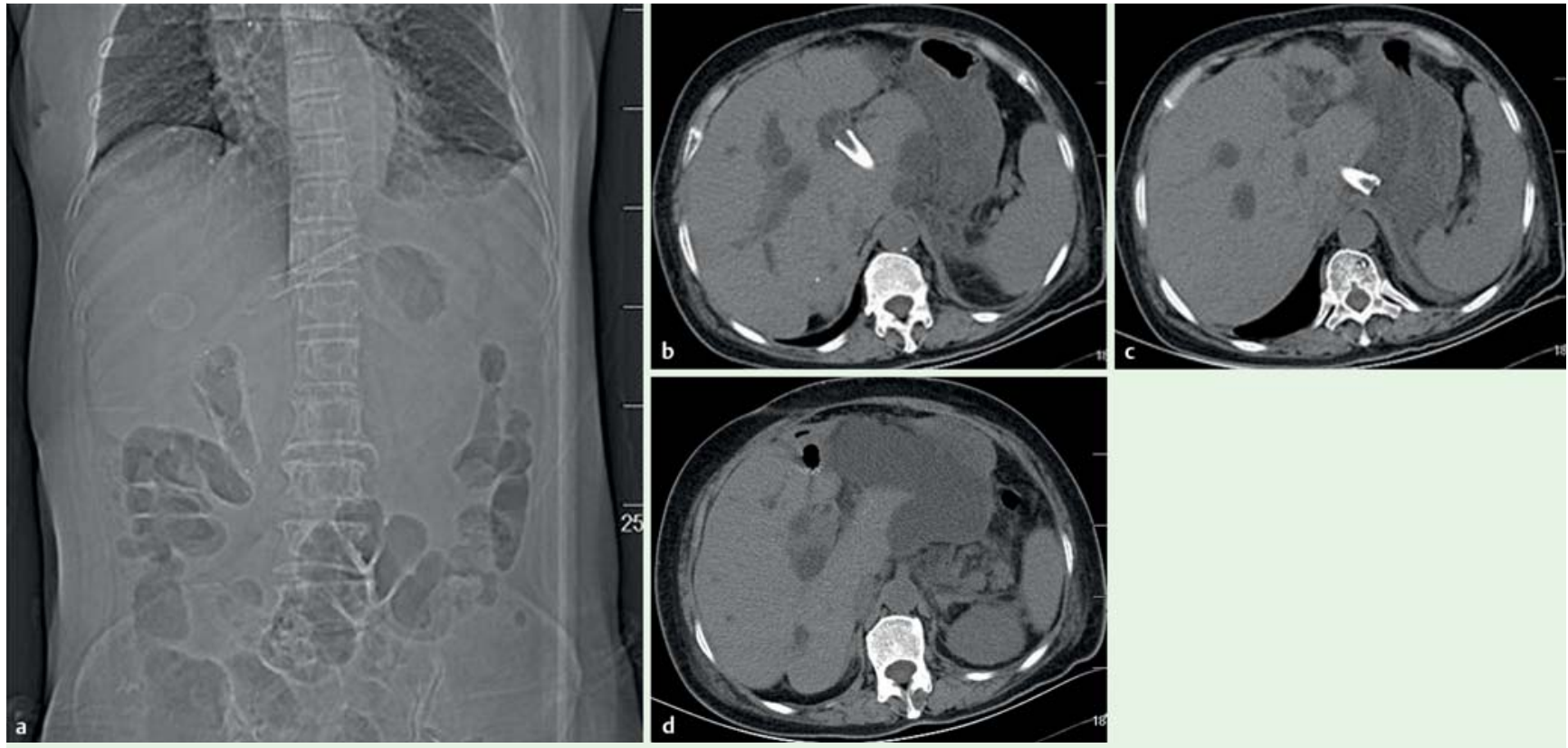

Fig. 1 Computed tomography (CT) scan images showing: $\mathbf{a}, \mathbf{b}, \mathbf{c}$ the migrated stent; $\mathbf{d}$ an abdominal fluid collection within the omental bursa
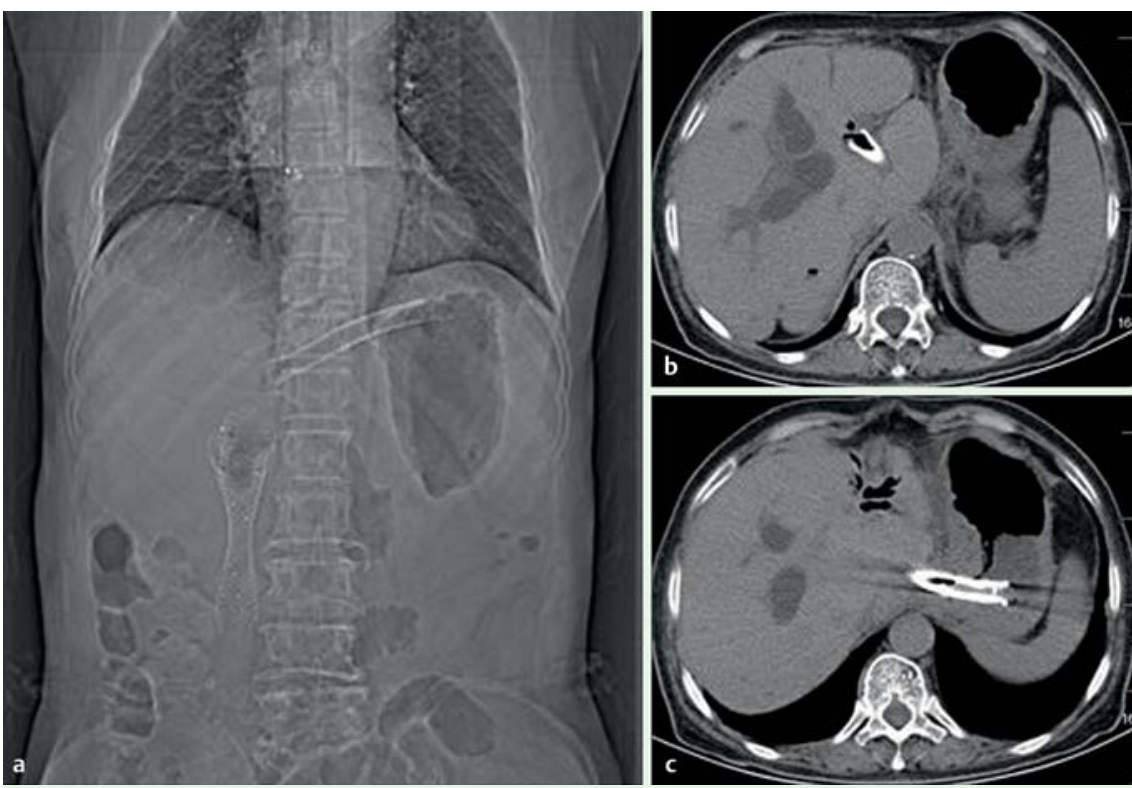

Fig. 2 Computed tomography (CT) scan images approximately 2 months later showing the repositioned stents still in place.

Endoscopic ultrasound (EUS)-guided hepaticogastrostomy with a fully covered metal stent is an option for malignant biliary obstruction after a failed endoscopic retrograde cholangiopancreatography (ERCP) [1-3]; however, migration of the stent can be a fatal complication [3,
4]. We report a case in which a migrated stent was successful reset using a foreign body forceps.

A 73-year-old woman developed abdominal pain and fever on the third day after EUS-guided hepaticogastrostomy with a metal stent (WallFlex Biliary RX, fully

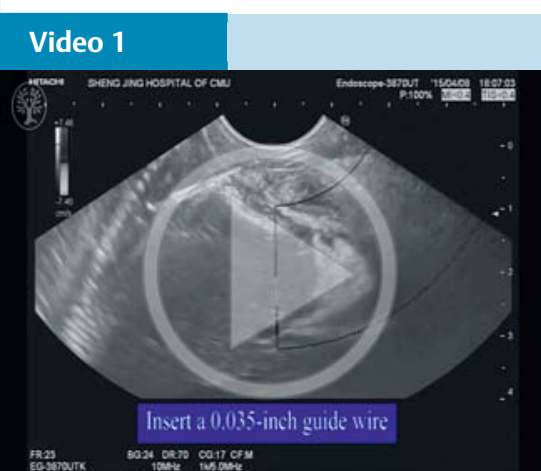

Endoscopic ultrasound (EUS)-guided repositioning of a migrated metal stent: a 0.035 -inch guidewire is passed through the migrated stent via a 19G flexible EUS aspiration needle and the transmural tract is enlarged by balloon dilation; the stent is successfully repositioned using foreign body forceps and a new longer stent is implanted inside the original; finally a drainage tube is inserted into the fluid collection.

covered stent system; Boston Scientific, Galway, Ireland). A computed tomography (CT) scan showed that stent migration had occurred ( $\odot$ Fig. 1 a, $\odot$ Fig. 1 b, $\odot$ Fig. $1 \mathrm{c}$ ) and an abdominal fluid collection had developed in the omental bursa ( $\bullet$ Fig. 1 d). 
We performed a puncture with a 19G flexible EUS aspiration needle (Expect; Boston Scientific, Menomonie, Wisconsin, USA) and inserted a 0.035-inch guidewire (METII-35-480 Tracer Metro Direct Wire Guide; Cook Medical, Limerick, Ireland) through the migrated stent, before enlarging the transmural tract by balloon dilation (Balloon dilation catheter; Changzhou Jiuhong Medical Instrument Company Limited, Changzhou, China). We then successfully reset the stent using a foreign body forceps (Rat tooth forceps; Shanghai Alton Medical Instrument Company Limited, Shanghai, China), implanted a new longer stent $(10 \mathrm{~mm} \times 80 \mathrm{~mm})$ inside the original one, and inserted a drainage tube (Liguory nasal biliary drainage catheter; Cook Medical) into the abdominal fluid collection ( Video 1 ). The patient was discharged from the hospital 4 days later. The stents functioned well for the following 2 months ( $\mathbf{F i g . 2}$ ).

This case illustrates that the omental bursa is an appropriate anastomotic choice for endoscopic operations. The abdominal fluid collection and migrated stent were restricted to the omental bursa, which thereby reduced the risk of serious consequences and facilitated endoscopic treatment. Therefore, we should learn to find the omental bursa by recognizing important ligaments during EUS [5].

Endoscopy_UCTN_Code_CPL_1AL_2AD

Competing interests: None

\section{Shupeng Wang, Jintao Guo, Siyu Sun, Xiang Liu, Sheng Wang, Nan Ge, Guoxin Wang}

Endoscopy center, Shengjing Hospital of China Medical University, Shenyang, China

\section{References}

1 Giovannini M, Dotti M, Bories E et al. Hepaticogastrostomy by echoendoscopy as a palliative treatment in a patient with metastatic biliary obstruction. Endoscopy 2003; 35: 1076-1078

2 Bories E, Caillol F, Pesenti C et al. Short-term results after hepaticogastrostomy guided by echo-endoscopy: Monocentric retrospective study. Endosc Ultrasound 2014; 3 (Suppl. 01): S14
3 Park do $H$. Endoscopic ultrasonographyguided hepaticogastrostomy. Gastrointest Endosc Clin N Am 2012; 22: 271 - 280

4 Martins FP, Rossini LG, Ferrari AP et al. Migration of a covered metallic stent following endoscopic ultrasound-guided hepaticogastrostomy: fatal complication. Endoscopy 2010; 42 (Suppl. 01): E126-E127

5 Sharma M, Rai P, Rameshbabu CS et al. Imaging of peritoneal ligaments by endoscopic ultrasound (with videos). Endosc Ultrasound 2015; 4: 15-27

Bibliography

Dol http://dx.doi.org/

10.1055/s-0042-100454

Endoscopy 2016; 48: E28-E29

(c) Georg Thieme Verlag KG

Stuttgart · New York

ISSN 0013-726X

Corresponding author

Siyu Sun, MD

The Shengjing Hospital, China Medical University No. 36, Sanhao Street

Shenyang

Liaoning Province 110004

China

Fax: +86-24-23892617

sunsy@sj-hospital.org

sun-siyu@163.com 